\title{
Multipotent Bone Marrow Stem Cell
}

National Cancer Institute

\section{Source}

National Cancer Institute. Multipotent Bone Marrow Stem Cell. NCI Thesaurus. Code C41058.

A specialized, self-renewing cell in the bone marrow that has the capacity to differentiate into a cell with a particular function. 